\title{
Cloning, Polymorphism and Tissue Expression of TAC3 Gene in Sheep
}

\author{
Wenping Hu${ }^{1}$, Xiangyu Wang ${ }^{1}$, Xiaodi Sun ${ }^{2}$, Ran $\mathrm{Di}^{1}$, Qiuyue Liu ${ }^{1}$, Zhangyuan \\ Pan $^{1}$, Xiaofei Guo ${ }^{1}$, Xiaohan Cao ${ }^{1}$, Jinyu Wang ${ }^{2}$, Yingjie Zhang ${ }^{3}$, Mei Jin ${ }^{4}$, Yuze \\ Yang $^{5}$ and Mingxing $\mathrm{Chu}^{1 *}$ \\ ${ }^{1}$ Institute of Animal Science, Chinese Academy of Agricultural Sciences, Beijing \\ 100193, P.R. China. \\ ${ }^{2}$ College of Animal Science and Technology, Yangzhou University, Yangzhou 225009, \\ P.R. China. \\ ${ }^{3}$ College of Animal Science and Technology, Hebei Agricultural University, Baoding \\ 071000, P.R. China. \\ ${ }^{4}$ College of Life Science, Liaoning Normal University, Dalian 116029, P.R. China. \\ ${ }^{5}$ Beijing General Station of Animal Husbandry, Beijing, 100101, P.R. China.
}

Wenping Hu and Xiangyu Wang contributed equally.
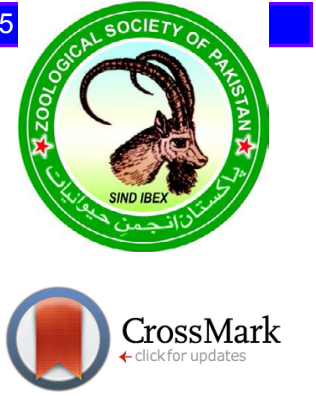

\begin{abstract}
A B S T R A C T
TAC3 gene is related to the regulation of animal reproductive function. Here we tried to find out the association of the expression and polymorphism of TAC3 gene with the estrus of sheep. TAC3 expression in uterus and pituitary gland increased in estrus of Small Tail Han sheep and Tan sheep. The TAC3 expression level in uterus might relate with estrus of sheep. Two mutations of TAC3 were found in intron 1 (C327T) and exon 2 (G1803A) separately. Although there were significant differences of C327T/G1803A genotype distributions in five different sheep breeds, it did not relate with the year-round estrus. The relationship between these polymorphisms of $T A C 3$ and the litter size of Small Tail Han sheep was not found.
\end{abstract}

Article Information
Received 03 March 2017
Revised 09 March 2019
Accepted 11 September 2019
Available online 17 April 2020
Authors' Contribution
WH, XW and MC designed the
experiments. ZP, XG and XC collected
the samples. XS performed the
experiments. WH wrote the article.
WH and XW analyzed the data.
Key words
TAC3 gene, Small Tail Han sheep,
Tan sheep, Polymorphism, Tissue
expression

\section{INTRODUCTION}

$\mathrm{M}$ any peptides with neurotransmitter activity have been identified including acetylcholine and noradrenaline, in addition to the classical neurotransmitters. Neurokinin $\mathrm{B}(\mathrm{NKB}$, encoded by $T A C 3)$ is a member of the tachykinin superfamily of neuropeptides that includes substance $P$ and neurokinin A (Almeida et al., 2004). NK3-R is cognate G protein-coupled receptor (NKB's receptor) which encoded by TACR3. Mutations in TAC3 and TACR3 encoding this ligand-receptor pair were identified in a Turkish population of normosmic Idiopathic Hypogonadotropic Hypogonadism (nIHH) patients (Topaloglu et al., 2009). Genome-wide single nucleotide polymorphism (SNP) analysis was performed, four homozygous mutations were found in nine IHH families, which caused three amino acid changes (M90T, G93N, P353S) (Topaloglu et al., 2009). As a neurotransmitter, NKB is primarily expressed in the central and peripheral nervous system, such as the human hypothalamus and basal forebrain. NKB is also expressed

\footnotetext{
* Corresponding author: mxchu@263.net 0030-9923/2020/0004-1541 \$ 9.00/0

Copyright 2020 Zoological Society of Pakistan
}

in the outer syncytiotrophoblast of the placenta (Chawla et al., 1997). It may be associated with pre-eclampsia and pregnancy-induced hypertension.

The timely secretion of gonadal sex steroids is essential for the process of sexual maturity, including the initiation of puberty, the postpubertal maintenance of secondary sexual characteristics. It is also essential for the normal perinatal development of male external genitalia (Topaloglu et al., 2009). Normal gonadal steroid production requires the actions of the gonadotropins from pituitary gland. Follicle-stimulating hormone (FSH) and luteinizing hormone ( $\mathrm{LH})$ are controlled by the pulsatile delivery of gonadotropin releasing hormone $(\mathrm{GnRH})$ from the hypothalamus (Plant, 2008).

NKB and NK3-R could affect GnRH secretion (Topaloglu et al., 2009). Kisspeptin expressed in hypothalamic neurons is a regulator of GnRH secretion. Human, animal, cellular, and bioinformatic models have been instrumental in defining the genetic control of GnRH. Many genes were found to affect GnRH neuronal migration, such as KAL1, FGFR1, FGF8, NELF, PROK2, PROKR2. KISS1-R, GNRH1 were found to influence GnRH secretory activity, and GNRHR could affect pituitary GnRH responsiveness. NKB and NK3-R were 
the newest proteins on this list (Gianetti et al., 2010). NKB could also inhibit LH secretion (Navarro et al., 2009).

$T A C 3$ gene is related to the regulation of animal reproductive function (Loffler et al., 2004; Page et al., 2000; Pintado et al., 2003). Many factors would influence the estrus of animals. The genetics and environment including temperature, nutrition and photoperiod were considered as the main factors (Zhao et al., 2019). For seasonal estrous animals, photoperiod plays a vital role in the regulation of seasonal estrus following environmental changes (Olcese, 1995). By the different estrous reaction, animals could be classified into long-day estrous animals and short-day estrous animals. Hamster and horse are long-day estrous animals, while deer and some sheep, like Tan sheep, Suffolk, and Texel sheep are short-day estrous animals. However, some animals do not have obviously seasonal estrus and could be in estrus all the year round, which called all year-round estrous animals, such as Wistar rat, cattle, swine, White Dorper sheep and Small Tail Han sheep. The year-round estrus of sheep has a considerable value, and it helps to improve productivity and bring economic benefit. As all year-round estrous animals, Small Tail Han sheep has high fecundity, and it is a unique genetic resource in China. This research aimed to find whether $T A C 3$ is associated with year-round estrus of sheep, like Small Tail Han sheep, and to provide some useful information for the molecular breeding to cultivate high fecundity sheep.

\section{MATERIALS AND METHODS}

269 Small Tail Han sheep were fed in Beijing Shengsifuming LLC (Changping, Beijing, China), and 180 Tan sheep were fed in Tan sheep breeding field (Yanci, Ningxia, China). These sheep were all pluriparous ewe and lambed in the same year. Ten $\mathrm{mL}$ blood sample per ewe were collected from these sheep. Genomic DNA was extracted by Phenol/chloroform extracting method, and stored at $-20^{\circ} \mathrm{C}$.

Five primers were designed according to sheep TAC3 sequences (GenBank No: NC_007303) and synthesized in Sangon Biotech (Shanghai) Co. Ltd. (Table I).

The PCR amplification program was: $95^{\circ} \mathrm{C}$ for $5 \mathrm{~min}$, 34 cycles of $95^{\circ} \mathrm{C}$ for $30 \mathrm{~s}$, annealing for $30 \mathrm{~s}$ (annealing temperature was shown in Table 1), and $72^{\circ} \mathrm{C}$ for $1 \mathrm{~min}$ and a final extension at $72^{\circ} \mathrm{C}$ for $5 \mathrm{~min}$. The PCR mixture contained $1 \mu \mathrm{L}$ of genomic DNA (50-100 ng/ $\mu \mathrm{L}), 10 \mu \mathrm{L}$ $2 \times$ Taq PCR Master Mix (Biomed, Beijing, P.R. China), $0.5 \mu \mathrm{L}(20 \mu \mathrm{M})$ each of forward and reverse primers, and 8

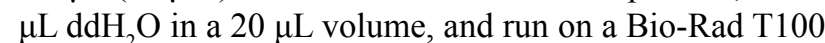
Thermal Cycler (Bio-Rad, California, USA).

PCR products were recovered using Agarose Gel
DNA Fragment Recovery Kit Ver. 2.0 (TaRaKa), and then ligated into the pMD19-T vector at $16^{\circ} \mathrm{C}$ overnight. After ligation, DNA was transformed into the competent cell (Escherichia coli Top10). Positive clones were identified by the restriction enzyme and then sequenced by Sangon Biotech (Shanghai) Co. Ltd.

Small Tail Han sheep on spring estus, spring diestrus, and fall estus condition, Tan sheep on spring anestrus, fall estus and fall diestrus were selected, and tissue samples were collected from three sheep on each estrus condition. Total RNA was extracted by RNA. cDNA was synthesized Prime Script TM RT reagent kit (TaKaRa, Dalian, China). Real-time PCR amplification reaction mixture containing $0.4 \mu \mathrm{L}$ of each primer $(10 \mu \mathrm{M})$ (forward primer: GCCAGCGTAGGTCCTAAGGA; reverse primer: AGACCCACAAAGAAGTCATGCA), $2 \mu \mathrm{L}$ of cDNA, 10 $\mu \mathrm{L}$ of SYBR Green Real-time PCR Master Mix (2×), 0.4 $\mu \mathrm{L}$ of ROX Reference Dye II (50×) and $6.8 \mu \mathrm{L}$ of ddH2O in $20 \mu \mathrm{L}$ volume. The amplication condition was $95^{\circ} \mathrm{C}$ for $5 \mathrm{~min}$, followed by 40 cycles of $95^{\circ} \mathrm{C}$ for $15 \mathrm{~s}, 60^{\circ} \mathrm{C}$ for 30 $\mathrm{s}$ and $72{ }^{\circ} \mathrm{C} 20 \mathrm{~s}$, and then $72{ }^{\circ} \mathrm{C} 2 \mathrm{~min}$. The dissociation curve was analyzed after amplification.

Statistical analyses were carried out using SPSS 15.0 software (SPSS Inc, Chicago, IL, USA).

\section{RESULTS AND DISCUSSION}

To know the association between TAC3 gene expression and year-round estrus of sheep, real-time qPCR was used to detect mRNA expression of TAC3 in the hypothalamus, pituitary gland, ovary, uterus, adrenal gland and pineal gland in different estrus of 2.5 years-old Small Tail Han sheep and Tan sheep (Table II). The results showed that the TAC3 gene expressed in six tissues of different estrus. The TAC3 expression level in the uterus in fall estrus of Tan sheep $(162.91 \pm 13.78)$ was remarkably higher than that in spring estrus $(23.87 \pm 8.43)$ and fall estrus $(15.29 \pm 2.56)$ of Small Tail Han sheep $(P<0.01)$. The TAC3 expression level in the uterus in spring estrus $(23.87 \pm 8.43)$ and fall estrus (15.29 \pm 2.56$)$ of Small Tail Han sheep was higher than that in spring diestrus of Small Tail Han sheep $(0.29 \pm 0.08)$ and that in spring anestrus of Tan sheep $(0.32 \pm 0.14)$. The TAC3 expression level in the pituitary gland in spring estrus and fall estrus of Small Tail Han sheep, and fall estrus of Tan sheep were significantly higher than that in spring diestrus of Small Tail Han sheep, and spring anestrus and fall diestrus of Tan sheep $(P<$ 0.01 ). It suggested that $T A C 3$ expression in uterus and pituitary gland increased in estrus of both sheep breeds. A very high $T A C 3$ expression level in uterus might be essential to drive Tan sheep estrus. It suggested the TAC3 expression level in uterus might affect seasonal estrus of Tan sheep. 
Table I. Primer sequence, amplified region, fragment size and annealing temperature for Small Tail Han sheep TAC3 gene.

\begin{tabular}{|c|c|c|c|c|}
\hline Primers & Primer sequence $\left(5^{\prime} \rightarrow 3^{\prime}\right)$ & Amplified region & Fragment size (bp) & Annealing temperature $\left({ }^{\circ} \mathrm{C}\right)$ \\
\hline \multirow[t]{2}{*}{$\mathrm{P} 1$} & F:TGCTCTTCCACCCTTAGTAACCT & Intron 1 & 836 & 52 \\
\hline & R:TCTCCTCCACAACTGAACCC & & & \\
\hline \multirow[t]{2}{*}{ P2 } & F:TTGGGATGAGACAGGAGTAGGATG & Intron 1 & 822 & 52 \\
\hline & R:GCATAACCGCTGGGAGTTTGTT & & & \\
\hline \multirow[t]{2}{*}{ P3 } & F: GTCTCCCAAATCTTGCTGCGTC & Exon 2- Exon 3 & 979 & 57 \\
\hline & R:CCTTAGCCCACCCTCTCTGTCTAC & & & \\
\hline \multirow[t]{2}{*}{ P4 } & F:TGGCTTCTTGAATGATTGAGGG & Exon3- Exon 5 & 1063 & 54 \\
\hline & R:CTACAAAGAGGGTTCCAAACGCAGC & & & \\
\hline \multirow[t]{2}{*}{ P5 } & F:TGGTGGGATACAGAAACAGA & Exon 5 and 3'flank & 865 & 58 \\
\hline & R:AGGCTGGAAAGAGATGAGAAAGA & & & \\
\hline
\end{tabular}

Table II. Expression level of TAC3 mRNA in different tissues of Small Tail Han and Tan sheep.

\begin{tabular}{|c|c|c|c|c|c|c|c|}
\hline Breeds & Estrus & Pituitary gland & Hypothalamus & Ovary & Uterus & Adrenal gland & Pineal gland \\
\hline \multirow{3}{*}{$\begin{array}{l}\text { Small } \\
\text { Tail Han } \\
\text { Sheep }\end{array}$} & Spring Estrus & $3.31 \pm 0.97^{\mathrm{A}}$ & $0.15 \pm 0.04^{\mathrm{C}}$ & $3.96 \pm 1.42^{\mathrm{AB}}$ & $23.87 \pm 8.43^{\text {В }}$ & $0.03 \pm 0.01^{\mathrm{B}}$ & $0.12 \pm 0.02^{\mathrm{C}}$ \\
\hline & Spring Diestrus & $0.23 \pm 0.06^{\mathrm{B}}$ & $0.80 \pm 0.20^{\mathrm{ABC}}$ & $1.17 \pm 0.48^{\mathrm{B}}$ & $0.29 \pm 0.08^{\mathrm{C}}$ & $0.06 \pm 0.01^{\mathrm{B}}$ & $0.31 \pm 0.04^{\mathrm{BC}}$ \\
\hline & Fall Estrus & $2.63 \pm 1.02^{\mathrm{A}}$ & $0.38 \pm 0.05^{\mathrm{ABC}}$ & $5.37 \pm 1.23^{\mathrm{AB}}$ & $15.29 \pm 2.56^{\mathrm{B}}$ & $0.28 \pm 0.03^{\mathrm{B}}$ & $0.55 \pm 0.09^{\mathrm{B}}$ \\
\hline \multirow{3}{*}{$\begin{array}{l}\text { Tan } \\
\text { Sheep }\end{array}$} & Spring Anestrus & $0.52 \pm 0.23^{\mathrm{B}}$ & $0.86 \pm 0.23^{\mathrm{AB}}$ & $2.64 \pm 1.26^{\mathrm{AB}}$ & $0.32 \pm 0.14^{\mathrm{C}}$ & $0.07 \pm 0.03^{\mathrm{B}}$ & $0.36 \pm 0.13^{\mathrm{BC}}$ \\
\hline & Fall Estrus & $2.95 \pm 1.11^{\mathrm{A}}$ & $0.25 \pm 0.05^{\mathrm{BC}}$ & $5.88 \pm 0.52^{\mathrm{A}}$ & $162.91 \pm 13.78^{\mathrm{A}}$ & $0.16 \pm 0.03^{\mathrm{B}}$ & $0.15 \pm 0.03^{\mathrm{C}}$ \\
\hline & Fall Diestrus & $0.51 \pm 0.17^{\mathrm{B}}$ & $1.02 \pm 0.14^{\mathrm{A}}$ & $1.02 \pm 0.14^{\mathrm{B}}$ & $1.08 \pm 0.27^{\mathrm{BC}}$ & $1.15 \pm 0.41^{\mathrm{A}}$ & $1.00 \pm 0.07^{\mathrm{A}}$ \\
\hline
\end{tabular}

$\mathrm{A}, \mathrm{B}, \mathrm{C}$ means the $\mathrm{P}$ value $<0.01$. The number after " \pm " represents standard error.

Table III. Allele and genotype frequencies of the SNP in TAC3 in five sheep breeds.

\begin{tabular}{|c|c|c|c|c|c|c|c|}
\hline Breed & & & Small Tail Han sheep & White Dorper & Tan sheep & Suffolk & Texel \\
\hline \multirow[t]{7}{*}{$\mathrm{C} 327 \mathrm{~T}$} & Number & & 185 & 47 & 56 & 35 & 35 \\
\hline & \multirow{3}{*}{$\begin{array}{l}\text { Genotype } \\
\text { frequency }\end{array}$} & $\mathrm{CC}$ & $0.78(145)$ & $0.96(45)$ & $0.59(33)$ & $0.77(27)$ & $1.00(35)$ \\
\hline & & $\mathrm{CT}$ & $0.19(34)$ & $0.04(2)$ & $0.32(18)$ & $0.23(8)$ & $0(0)$ \\
\hline & & TT & $0.03(6)$ & $0(0)$ & $0.09(5)$ & $0(0)$ & $0(0)$ \\
\hline & \multicolumn{2}{|c|}{ Allele frequen- $\mathrm{C}$} & 0.88 & 0.98 & 0.75 & 0.89 & 1 \\
\hline & cy & $\mathrm{T}$ & 0.12 & 0.02 & 0.25 & 0.11 & 0 \\
\hline & $\mathrm{H}-\mathrm{W}$ test & $\chi^{2}$ & 4.5 & 0.02 & 1.14 & 0.58 & -- \\
\hline \multirow[t]{7}{*}{ G1803A } & Number & & 193 & 41 & 54 & 38 & 43 \\
\hline & \multirow{3}{*}{$\begin{array}{l}\text { Genotype } \\
\text { frequency }\end{array}$} & AA & $0.04(8)$ & $0(0)$ & $0.18(10)$ & $0(0)$ & $0(0)$ \\
\hline & & $\mathrm{AG}$ & $0.29(56)$ & $0.07(3)$ & $0.52(28)$ & $0.26(10)$ & $0(0)$ \\
\hline & & GG & $0.67(129)$ & $0.93(38)$ & $0.30(16)$ & $0.74(28)$ & $1.00(43)$ \\
\hline & \multirow{2}{*}{$\begin{array}{l}\text { Allele frequen- } \\
\text { cy }\end{array}$} & A & 0.19 & 0.04 & 0.44 & 0.13 & 0 \\
\hline & & G & 0.81 & 0.96 & 0.56 & 0.87 & 1 \\
\hline & $\mathrm{H}-\mathrm{W}$ test & $\chi^{2}$ & 0.37 & 0.06 & 0.14 & 0.87 & -- \\
\hline
\end{tabular}

Note: The numbers in the brackets are the individuals that belong to the respective genotypes. 
As a critical central regulator of gonadal function, TAC3 might relate to the reproduction of human or animals (Pintado et al., 2003). Navarro et al. found TAC3 and TACR 3 genes were expressed in the Arc of female mice. The expression was inhibited by estradiol (E2) (Navarro et al., 2009). In the hypothalamus of postmenopausal women, TAC3 gene expression was elevated. Estrogen replacement decreased the level of TAC 3 expression within hypothalamus cells, and the number of NKB mRNAexpressing neurons was also decreased. In ovariectomized rats, TAC3 gene expression was elevated, and the expression level reduced after estrogen treatment. Plasma concentrations of NKB were elevated in pre-eclampsia and pregnancy-induced hypertension (Page et al., 2000). D'Anna et al., 2004 also found NKB plasma levels in the pre-eclamptic were significantly higher than controls (D'Anna et al., 2004). The elevated levels of NKB in early pregnancy may be an indicator of hypertension and preeclampsia (Page et al., 2000).

Five pairs of primers (P1 to P5) of TAC3 gene were designed to clone Small Tail Han sheep TAC3 DNA sequence (as shown in Figure A). The PCR products were cloned and sequenced, a 3296 bp DNA sequence without exon 1 of TAC3 was obtained. TAC3 gene was also cloned from Tan sheep. By sequence alignment with Tan sheep (seasonal estrous sheep), two mutations were found in intron 1 (C327T) and exon 2 (G1803A) (as shown in Figure B). The PCR products of primer P1 or P3 were digested entirely with $B I P$ I or $S m l$ I restriction endonuclease, and genetic polymorphisms of TAC3 were investigated by PCR-RFLP. Three genotypes, CC (327/469 bp), CT (327/469/796 bp) and TT (796 bp), were found after digested with BIP I. Three genotypes, AA (979bp), AG (390/589/979 bp) and GG (390/589 bp) were found after digested with $\mathrm{Sml} \mathrm{I} \mathrm{(as} \mathrm{shown} \mathrm{in} \mathrm{Figure} \mathrm{C).}$

The frequencies of these alleles and genotypes were calculated in year-round estrous sheep breeds (Small Tail Han sheep, White Dorper sheep) and seasonal estrous sheep breeds (Tan, Suffolk, and Texel sheep) by PCRRFLP (Table III). At locus of C327T, the dominant allele in these five sheep breeds was C. Texel sheep only had CC genotype, White Dorper sheep and Suffolk sheep had CC/ TT genotype, while Small Tail Han sheep and Tan sheep had all three genotypes, CC/CT/TT. At locus of G1803A, the dominant allele in these five sheep breeds was G. Texel sheep only had GG genotype, White Dorper sheep and Suffolk sheep had GG/AA genotype, while Small Tail Han sheep and Tan sheep had all three genotypes, GG/AG/AA. There was no association between the frequencies of these alleles and genotypes with the different estrous breeds. Moreover, the difference of the C327T/G1803A genotype distributions of $T A C 3$ in five sheep breeds was analyzed (Table IV). It displayed the polymorphisms of TAC3 gene was not related with the year-round estrus.

A

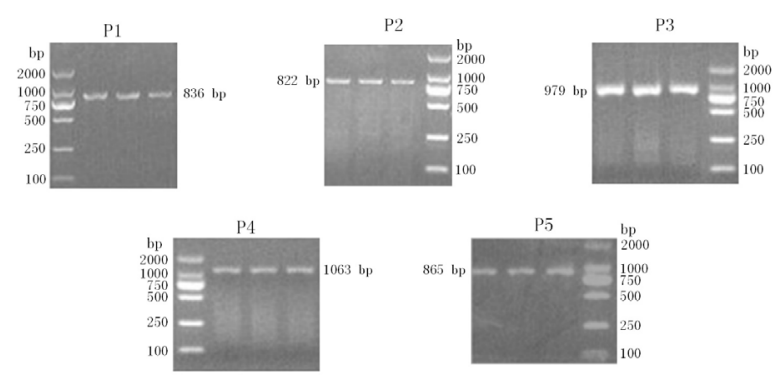

B

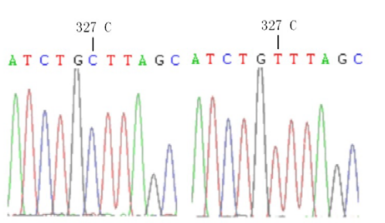

C $\quad P 1$
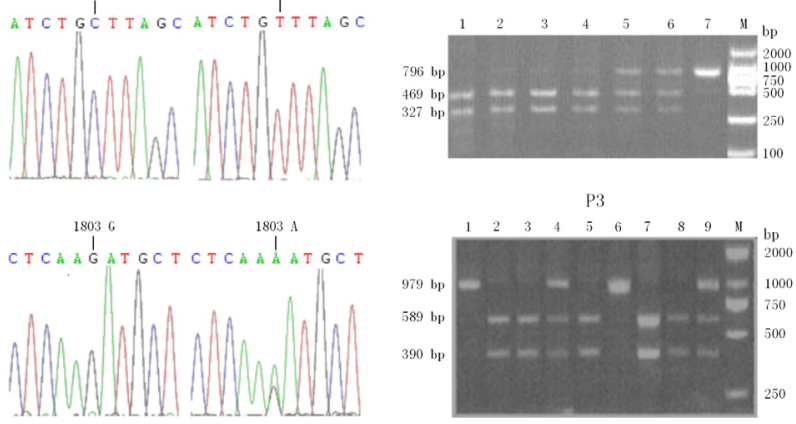

Fig. (A) PCR products of P1 - P5 primers. (B) Nucleotide mutations at locus 327 and locus 1803 in sheep TAC3 gene. (C) Electrophoresis analysis of RFLP products of primer P1 and P3. P1: Bands 1, 2, 3 and 4 were CC genotype; Bands 5 and 6 were CT genotype; Band 7 was TT genotype; M: DNA Marker 2000. P3: Bands 1 and 6 were AA genotype; Bands 2, 3, 5,7 and 8 were GG genotype; Bands 4 and 9 were AG genotype; M: DNA Marker 2000.

Least squares mean and standard error for litter size of different genotypes in 327 and 1803 loci of TAC3 gene in Small Tail Han sheep were analyzed (Table V). There was no significant difference $(P>0.05)$ of litter size was found in different genotypes for the two loci.

Although many studies have been done on TAC3 in human and rodents, the study in sheep is very rare. In this study, we tried to find out the association of polymorphism and expression of TAC3 gene with the estrus and fertility of sheep. Two mutations of TAC3 were found in intron 1 (C327T) and exon 2 (G1803A) separately. TAC3 expression in uterus and pituitary gland increased in estrus of Small Tail Han sheep and Tan sheep, and TAC3 expression level in uterus might relate with estrus of sheep. It implied the expression of TAC3 might relate with estrus of sheep. The mechanism of year-round estrus of sheep is still unknown. However, it is essential for the molecular 
Table IV. Test of difference of the C327T/G1803A genotype distributions of TAC3 in five sheep breeds.

\begin{tabular}{lllll}
\hline Breed & Small Tail Han sheep & White Dorper & Tan sheep & Suffolk \\
\hline White Dorper & $7.72 * / 11.18^{* *}$ & & & \\
Tan sheep & $9.02 * / 28.38^{* * *}$ & $19.00^{* * * / 38.06 * * *}$ & & \\
Suffolk & $1.45 / 1.87$ & $13.75^{* * / 5.18}$ & $4.86 / 19.61 * * *$ & $19.24 * * * / 49.75^{* * *}$ \\
Texel & $9.25 * * / 19.56^{* * *}$ & $1.53 / 3.26$ & $14.65^{* * * / 12.91 * *}$ \\
\hline
\end{tabular}

breeding to cultivate high fecundity sheep. More research about TAC3 and the mechanism of year-round estrus need to be performed.

Table V. Least squares mean and standard error for litter size of different genotypes in two loci of $T A C 3$ gene in Small Tail Han sheep.

\begin{tabular}{llll}
\hline Locus & Genotype & Number of ewes & Litter size \\
\hline 327 & CC & 145 & $2.34^{\mathrm{a}} \pm 0.08$ \\
& CT & 34 & $2.30^{\mathrm{a}} \pm 0.16$ \\
& TT & 6 & $2.26^{\mathrm{a}} \pm 0.21$ \\
1803 & AA & 8 & $2.30^{\mathrm{a}} \pm 0.20$ \\
& AG & 56 & $2.31^{\mathrm{a}} \pm 0.14$ \\
& GG & 129 & $2.34^{\mathrm{a}} \pm 0.10$ \\
\hline
\end{tabular}

Note: Least squares means with the same superscript for the same pair of primer have no significant difference $(P>0.05)$.

\section{ACKNOWLEDGMENTS}

This work was supported by the National Natural Science Foundation of China (No. 31501941, No. 31472078, No. 31572371, No. 31501926), by Central Public-interest Scientific Institution Basal Research Fund (No.Y2017JC24, No. 2017ywf-zd-13, No. 2018ywf-yb-1, No. 2018ywf-yb-2), by The Agricultural Science and Technology Innovation Program of China (No. ASTIP-IAS13), by The Earmarked Fund for China Agriculture Research System (No. CARS-38).

\section{Ethics statement}

All the animals were cared for under guidelines comparable to those laid down by the Council on Animal Care and were approved by the Animal Ethics Committee of Chinese Academy of Agricultural Sciences for the use of animals in scientific research.

\section{Statement of conflict of interset}

The authors declare that there is no conflict of interests regarding the publication of this article.

\section{REFERENCES}

Almeida, T.A., Rojo, J., Nieto, P.M., Pinto, F.M., Hernandez, M., Martin, J.D. and Candenas, M.L., 2004. Tachykinins and tachykinin receptors: Structure and activity relationships. Curr. Med. Chem., 11: 2045-2081. https://doi. org/10.2174/0929867043364748

Chawla, M.K., Gutierrez, G.M., Young, W.S., McMullen, N.T. and Rance, N.E., 1997. Localization of neurons expressing substance $\mathrm{P}$ and neurokinin $\mathrm{B}$ gene transcripts in the human hypothalamus and basal forebrain. J. Comp. Neurol., 384: 429-442. https://doi.org/10.1002/ (SICI) 1096-9861(19970804)384:3<429::AID$\mathrm{CNE} 8>3.0 . \mathrm{CO} ; 2-5$

D’Anna, R., Baviera, G., Corrado, F., Crisafulli, A., Ientile, R., Buemi, M. and Squadrito, F., 2004. Neurokinin $\mathrm{B}$ and nitric oxide plasma levels in pre-eclampsia and isolated intrauterine growth restriction. Int. J. Obstetr. Gynaecol., 111:1046-1050. https://doi. org/10.1111/j.1471-0528.2004.00257.x

Gianetti, E., Tusset, C., Noel, S.D., Au, M.G., Dwyer, A.A., Hughes, V.A., Abreu, A.P., Carroll, J., Trarbach, E., Silveira, L.F., Costa, E.M., de Mendonça, B.B., de Castro, M., Lofrano, A., Hall, J.E., Bolu, E., Ozata, M., Quinton, R., Amory, J.K., Stewart, S.E., Arlt, W., Cole, T.R., Crowley, W.F., Kaiser, U.B., Latronico, A.C. and Seminara, S.B., 2010. TAC3/TACR3 mutations reveal preferential activation of gonadotropin-releasing hormone release by neurokinin B in neonatal life followed by reversal in adulthood. J. Clin. Endocrinol. Metab., 95: 2857-2867.

Loffler, S., Schulz, A., Hunt, S.P. and Spanel-Borowski, K., 2004. Increased formation of corpora lutea in neurokinin 1-receptor deficient mice. Mol. Reprod. Dev., 68: 408-414. https://doi.org/10.1002/ mrd.20093

Navarro, V.M., Gottsch, M.L., Chavkin, C., Okamura, H., Clifton, D.K. and Steiner, R.A., 2009. Regulation of gonadotropin-releasing hormone secretion by kisspeptin/dynorphin/neurokinin B 
neurons in the arcuate nucleus of the mouse. $J$. Neurosci., 29: 11859-11866. https://doi.org/10.1523/ JNEUROSCI.1569-09.2009

Olcese, J., 1995. The mammalian pineal gland and reproduction. Controversies and strategies for future research. Adv. Exp. Med. Biol., 377:1-14. https://doi. org/10.1007/978-1-4899-0952-7_1

Page, N.M., Woods, R.J., Gardiner, S.M., Lomthaisong, K., Gladwell, R.T., Butlin, D.J., Manyonda, I.T. and Lowry, P.J., 2000. Excessive placental secretion of neurokinin B during the third trimester causes pre-eclampsia. Nature, 405: 797-800. https://doi. org/10.1038/35015579

Pintado, C.O., Pinto, F.M., Pennefather, J.N., Hidalgo, A., Baamonde, A., Sanchez, T. and Candenas, M.L., 2003. A role for tachykinins in female mouse and rat reproductive function. Biol. Reprod., 69: 940-946. https://doi.org/10.1095/biolreprod.103.017111
Plant, T.M., 2008. Hypothalamic control of the pituitarygonadal axis in higher primates: key advances over the last two decades. J. Neuroendocrinol., 20:719-726. https://doi.org/10.1111/j.13652826.2008.01708.x

Topaloglu, A.K., Reimann, F., Guclu, M., Yalin, A.S., Kotan, L.D., Porter, K.M., Serin, A., Mungan, N.O., Cook, J.R., Ozbek, M.N., 2009. TAC3 and TACR3 mutations in familial hypogonadotropic hypogonadism reveal a key role for Neurokinin B in the central control of reproduction. Nat. Genet., 41:354-358. https://doi.org/10.1038/ng.306

Zhao, Z., Yang, T., Qiao, L., He, Q. and Dai, Z., 2019. Reproductive characteristics of Dazu Black Goats: A newly discovered Chinese indigenous breed resource with high litter sizes. Pakistan J. Zool., 51: 399-403. 